\title{
Paternal genetic affinity between western Austronesians and Daic populations
}

\author{
Hui $\mathrm{Li}^{* 1,2}$, Bo Wen ${ }^{1}$, Shu-Juo Chen ${ }^{3,4}$, Bing Su${ }^{5}$, Patcharin Pramoonjago, \\ Yangfan Liu ${ }^{1}$, Shangling Pan ${ }^{7}$, Zhendong Qin ${ }^{1}$, Wenhong Liu ${ }^{1}$, Xu Cheng ${ }^{1}$, \\ Ningning Yang ${ }^{1}$, Xin Li1 ${ }^{1} 2$, Dinhbinh Tran ${ }^{8}$, Daru Lu ${ }^{1}$, Mu-Tsu Hsu ${ }^{3}$, \\ Ranjan Deka ${ }^{9}$, Sangkot Marzuki ${ }^{5}$, Chia-Chen Tan ${ }^{1}$ and Li Jin*1,10
}

\begin{abstract}
Address: ${ }^{1} \mathrm{MOE}$ Key Laboratory of Contemporary Anthropology and Center for Evolutionary Biology, School of Life Sciences and Institutes for Biomedical Sciences, Fudan University, Shanghai 200433, China, ${ }^{2}$ Department of Genetics, School of Medicine, Yale University, New Haven CT 06520, USA, ${ }^{3}$ Graduate Institute of Anthropology, Tzu Chi University, Hualien 970, Taiwan, China, ${ }^{4}$ Department of Anthropological Sciences, Stanford University, Stanford, CA 94305, USA, 5 Key Laboratory of Cellular and Molecular Evolution, Kunming Institute of Zoology, Chinese Academy of Sciences, Kunming 650223, China, ${ }^{6}$ Eijkman Institute for Molecular Biology, Jakarta, Indonesia, ${ }^{7}$ Department of Pathophysiology, Guangxi Medical University, Nanning 530021, China, ${ }^{8}$ Huê Medical College, Huê, Viêtnam, ${ }^{9}$ Center for Genome Information, Department of Environmental Health, University of Cincinnati, Cincinnati, OH 45267, USA and ${ }^{10}$ CAS-MPG Partner Institute for Computational Biology, SIBS, CAS, Shanghai 200013, China

Email: Hui Li* - LiHui.Fudan@gmail.com; Bo Wen - wenbocn@gmail.com; Shu-Juo Chen - Shujuo@stanford.edu; Bing Su - Sub@mail.kiz.ac.cn; Patcharin Pramoonjago - patcha@eijkman.go.id; Yangfan Liu - Liu.Yangfan@gmail.com; Shangling Pan - s.pan@gxmu.net.cn; Zhendong Qin - ZhenDong.Qin@gmail.com; Wenhong Liu - WenHLiu@hotmail.com; Xu Cheng - XuCheung@gmail.com; Ningning Yang - yang_ningning@hotmail.com; Xin Li - Lee_sharn@hotmail.com; Dinhbinh Tran - trandinhbinhvn@yahoo.com; Daru Lu - drlu@fudan.edu.cn; Mu-Tsu Hsu - mts.hsu@gmail.com; Ranjan Deka - dekar@ucmail.uc.edu; Sangkot Marzuki - Smarzuki@eijkman.go.id; Chia-Chen Tan - CCTan@fudan.edu.cn; Li Jin* - LJin007@gmail.com

* Corresponding authors
\end{abstract}

\section{Published: 15 May 2008}

BMC Evolutionary Biology 2008, 8:146 doi:10.1/86/147|-2|48-8-146
Received: 20 June 2007

Accepted: 15 May 2008

This article is available from: http://www.biomedcentral.com//47/-2/48/8/I46

(C) $2008 \mathrm{Li}$ et al; licensee BioMed Central Ltd.

This is an Open Access article distributed under the terms of the Creative Commons Attribution License (http://creativecommons.org/licenses/by/2.0), which permits unrestricted use, distribution, and reproduction in any medium, provided the original work is properly cited.

\begin{abstract}
Background: Austronesian is a linguistic family spread in most areas of the Southeast Asia, the Pacific Ocean, and the Indian Ocean. Based on their linguistic similarity, this linguistic family included Malayo-Polynesians and Taiwan aborigines. The linguistic similarity also led to the controversial hypothesis that Taiwan is the homeland of all the Malayo-Polynesians, a hypothesis that has been debated by ethnologists, linguists, archaeologists, and geneticists. It is well accepted that the Eastern Austronesians (Micronesians and Polynesians) derived from the Western Austronesians (Island Southeast Asians and Taiwanese), and that the Daic populations on the mainland are supposed to be the headstream of all the Austronesian populations.
\end{abstract}

Results: In this report, we studied 20 SNPs and 7 STRs in the non-recombining region of the I,509 Y chromosomes from 30 China Daic populations, 23 Indonesian and Vietnam Malayo-Polynesian populations, and II Taiwan aboriginal populations. These three groups show many resemblances in paternal lineages. Admixture analyses demonstrated that the Daic populations are hardly influenced by $\mathrm{Han}$ Chinese genetically, and that they make up the largest proportion of Indonesians. Most of the population samples contain a high frequency of haplogroup Ola-MII9, which is nearly absent in other ethnic families. The STR network of haplogroup Ola* illustrated that Indonesian 
lineages did not derive from Taiwan aborigines as linguistic studies suggest, but from Daic populations.

Conclusion: We show that, in contrast to the Taiwan homeland hypothesis, the Island Southeast Asians do not have a Taiwan origin based on their paternal lineages. Furthermore, we show that both Taiwan aborigines and Indonesians likely derived from the Daic populations based on their paternal lineages. These two populations seem to have evolved independently of each other. Our results indicate that a super-phylum, which includes Taiwan aborigines, Daic, and MalayoPolynesians, is genetically educible.

\section{Background}

Austronesian is one of the most important linguistic families, spread in most regions of Island Southeast Asia, the Pacific Ocean, and the Indian Ocean, and comprising more than one fifth of all the languages in the world [1]. This linguistic family was originally proposed by Murdock [2] by bringing two groups of speakers, i.e. Malayo-Polynesians (Island Southeast Asians (ISEA), Malagasy, Micronesians, and Polynesians) and Taiwan aborigines together as a monophyletic unit based on their linguistic similarity $[3,4]$. Later, Benedict found that another linguistic family in East Asia, Daic, has many resemblances with the socalled Austronesian, and therefore announced a superphylum of Austro-Tai [5]. Daic is a linguistic family located to the north of the ISEA groups, mainly in South China. Some Daic populations spread to Laos, Thailand, and as far as India [1]. Substantial resemblances among Taiwan aborigines, Malayo-Polynesians, and Daic speakers have been reported by ethnologists [6-10] and linguists [11-15], linking Taiwan aborigines and MalayoPolynesians to coastal populations in Southeast China, primarily Daic speakers and their ancestry, Baiyue.

The origin of Austronesian has always been a controversial subject in linguistics and other related fields. The Express Train Hypothesis, a well accepted linguistic theory on the origin of Austronesian $[3,4,16,17]$, postulates that proto-Austronesians originated in Taiwan and began to expand southward about 5,000-6,000 years ago by way of the Philippines and Eastern Indonesia. They eventually navigated eastward to Micronesia and Polynesia, and westward to Western Indonesia and Madagascar. The 'express train' refers to a rapid dispersal across the present Austronesian range starting from Eastern Indonesia. The hypothesis of the Taiwan origin of all the Austronesians (Taiwan Homeland Hypothesis or THH hereafter) is primarily based on the observation that a much higher linguistic diversity exists among languages of Taiwan aborigines than among the Malayo-Polynesians [3,4]. However, some linguists found evidences against the $\mathrm{THH}$, and suggested that Kalimantan or Sulawesi may be the homeland of Austronesian $[15,18,19]$. The THH was further challenged by ethnologists [6-9], archaeologists [10], and geneticists [20-25].
Genetic evidence has been equally controversial. Some mitochondrial DNA (mtDNA) studies suggested a Taiwan origin of Polynesians [20-22]. A recent mtDNA study on Taiwan aborigines found a root of the "Polynesian Motif" in Taiwan, which suggests that the THH may be confirmed in maternal lineages [26]. On the other hand, this theory was challenged in paternal lineages by the Y-Chromosome studies that showed a lack of resemblance between the Polynesians and Taiwan aborigines [23]. It was also challenged by other mtDNA studies, which suggest an Indonesian origin of Polynesians [24,25]. The conflicts in the genetic evidence can be attributed to the lack of evidence or populations from two crucial regions: (1) coastal populations in Southeast Asia ancestral to three Austronesian groups (Taiwan aborigines, ISEA, and Polynesians), and (2) ISEA populations including Indonesians from which Polynesians derived.

Another important factor in the genetic structure of Austronesians is that Eastern Austronesians are distinctly different from Western Austronesians (ISEA and Taiwan aborigines, Figure 1). Autosomal STR variation studies [27] revealed a pronounced genetic division between Polynesians and Western Austronesians. These studies suggest that the Polynesians might have undergone natural selection or have been admixed with Melanesians. This process changed their genetic structure $[16,20,28]$. There is also the possibility of genetic drift and founder effects during the dispersal of Polynesians. The genetic structure of Western Austronesians, especially that of the ISEA, is more pivotal to the origin of Austronesians (Figure 1). The high Y chromosome diversity of Indonesian populations, Bali and Sumba islanders, suggests that these populations have existed since the Palaeolithic age $[29,30]$. Because of this high genetic diversity, it appears that the ISEA, especially the Indonesians are not just of Taiwanese origin.

Here, we examined the THH of ISEA by studying the $\mathrm{Y}$ chromosome diversity of all relevant population groups such as that of the Daic, Indonesians, and Taiwan aborigines. We show that the paternal lineages of both ISEA and Taiwan aborigines derived from the Daic, although independently of each other. In addition, our findings indicate 


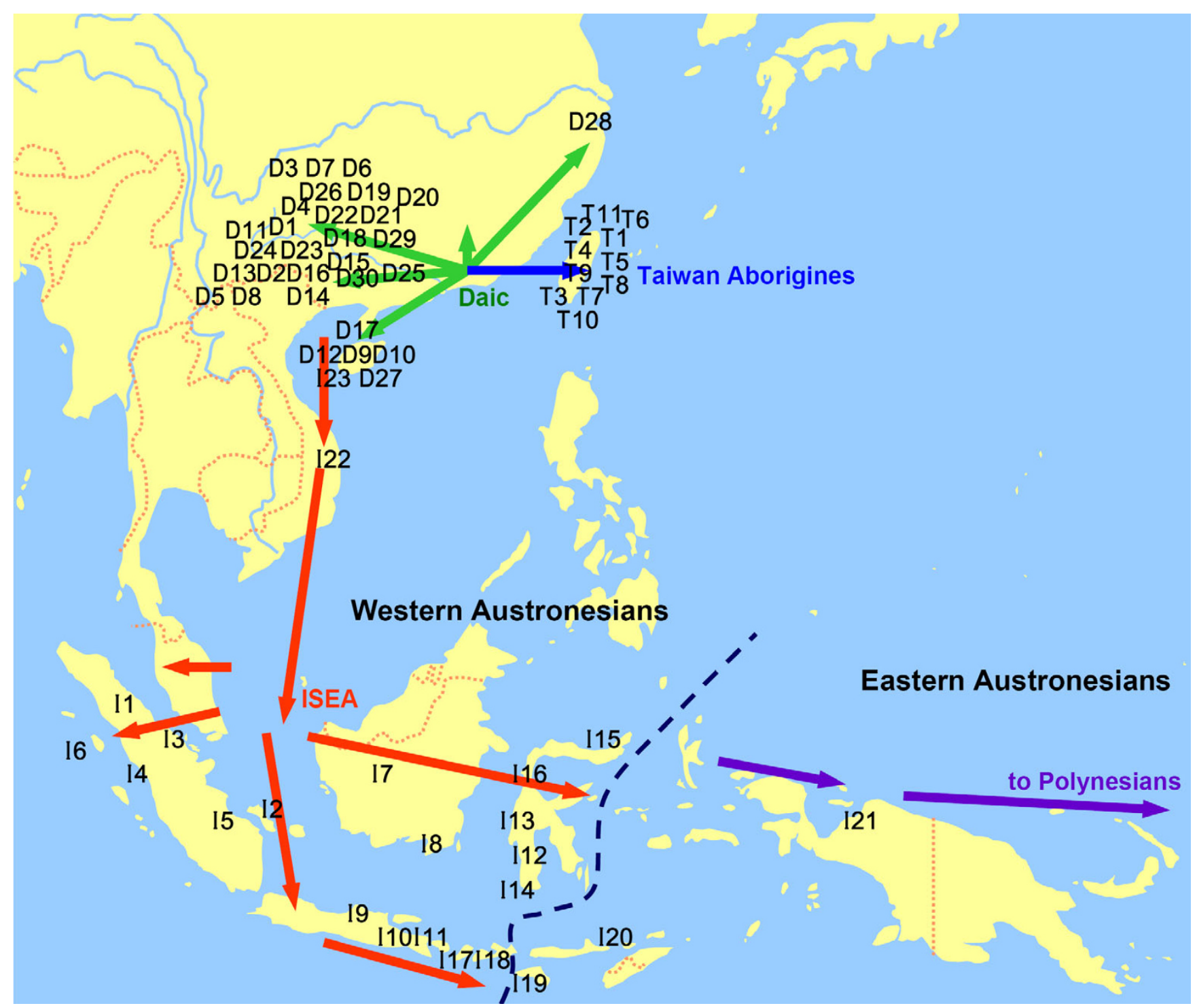

\section{Figure I}

Geographic distribution of sampled populations and migration routes suggested by $\mathbf{Y}$ chromosome analysis. The codes for the population samples are the same as those in Table I. Green arrows indicate expansion of Daic; blue arrows, Taiwanese; orange arrows, ISEA. The origin of Polynesians, purple arrows, remains controversial in paternal lineages.

that it is unlikely that Taiwan is the homeland of the paternal lineages of the ISEA populations.

\section{Results and Discussion}

To determine the genetic affinity between the Daic populations and the Western Austronesians, we typed twenty single nucleotide polymorphisms (SNPs) and seven short tandem repeats (STRs) in the non-recombining region of 1,509 Y chromosomes sampled from 30 Daic populations, 23 ISEA populations, and 11 Taiwan aboriginal populations (see Figure 1 for locations of the populations and Table 1 for population information). Almost all of the Daic populations in China and all of the Taiwan aboriginal populations were sampled in this study.

In addition, principal component (PC) analysis of 134 East Asian populations encompassing all linguistic groups in East and Southeast Asia was performed using the frequencies of haplogroups defined by SNPs. The result showed that Daic populations are closer to the Western Austronesian groups than any other East and Southeast Asian populations are (Figure 2), indicating a strong genetic affinity between Daic speakers and Western Austronesians. The separation of the Daic-ISEA-Taiwan clus- 
ter from the other ethnic groups is attributable to PC2 rather than to $\mathrm{PC} 1$, and $\mathrm{O}_{1} \mathrm{a}^{*}$ is the haplogroup that shows the strongest correlation with PC2 $\left(r^{2}=-0.875, P<\right.$ $10^{-4}$; see Additional file 1 for details). Furthermore, O1aM119 is the dominating haplogroup in Taiwan aborigines (average $77 \%$ ) ranging from $54 \%$ to $100 \%$ (Table 2, sum of O1a* and O1a2). This lineage is also highly prevalent in Daic speakers $(20.5 \%)$ and in ISEA (21.2\%), but not in the other East Asians (<5\%) [23,31-34]. Therefore, O1aM119 is expected to provide much information for delineating the relationship between the Daic and Western Austronesians.

The PC plot of Figure 2 indicates that some Daic populations are close to the Sino-Tibetan cluster. It is possible that Daic and Sino-Tibetan populations have a common ancestry, which might have resulted in their genetic resemblance. However, another explanation for this observation is that Daic populations in mainland East Asia may have been influenced by Han Chinese genetically as they coexisted as neighbors since around 2,500 years ago. Admixture analysis can estimate the proportions of assumed Daic or Han ancestry in the present Daic populations, and some Daic populations isolated from Han Chinese can be used as the parental population in this admixture analysis. Aboriginal populations on Hainan Island (Hlai, Jiamao, and Cun) and Taiwan Island are assumed to have been relatively isolated, as their cultures were little influenced by the exotic cultures on the mainland. Therefore, the genetic structures of these island aborigines might be the closest to that of ancestral Daic [35].

To estimate the assumed genetic influence of Han Chinese on the mainland Daic, we applied the Y SNP data of mainland Daic, Hainan aborigines, Taiwan aborigines, and Han Chinese [34] to our admixture analysis. For this analysis, we set the latter three pooled populations as the parental populations of mainland Daic. Our results show that the genetic contribution of the Hainan aborigines is very high $(2.145 \pm 0.927)$, while those of the Han Chinese $(-0.314 \pm 0.422)$ and Taiwan aborigines $(-0.831 \pm 0.662)$ are hardly detected. Here the negative values of the genetic contribution estimated by the ADMIX program suggest that there is no possible contributions to the present Daic populations. This result indicates that the paternal lineages of Daic populations are relatively undisturbed, and the genetic affinity between Daic and Western Austronesian populations has hardly been influenced by population admixture.

The ISEA populations may also be admixed. In our study, we assumed that the ISEA were mixed by three potential parental populations: Daic populations, Taiwan aborigines, and the indigenous populations of the Sunda Islands, who are similar to Papuans. We performed an admixture analysis on the Indonesians, and included data of the Papuans from the literature $[36,37]$ as one of the parental population structures in the analysis. Our analysis showed the following admixture proportions: Daic $(0.713$ $\pm 0.124)$, Taiwan $(0.143 \pm 0.125)$, and Papuans $(0.144 \pm$ 0.050 ), indicating that the contribution of the Daic ancestry on the Indonesians is the most dominant. There is some uncertainty in these data as our assumption that the ISEA population is an admixture can not be tested.

As the haplogroup $\mathrm{O} 1 \mathrm{a}^{*}$ is the most unique haplogroup of the Daic and Western Austronesian populations, we estimated pairwise genetic divergence between Daic, Indonesians, and Taiwan aborigines using seven STRs carried by O1a* individuals (see Table 3 for genetic distances and Additional file 2 for STR raw data). Our study shows that the divergence between Taiwan aborigines and Indonesians is the largest, and is about 3 -fold as much as that between the Daic group and Taiwan aborigines. The divergence between the Daic group and Indonesians is comparable to that between the Daic group and Taiwan aborigines. These findings indicate that the Indonesians and Taiwan aborigines are genetically closer to the Daic group than the two Western Austronesian groups are to each other. Furthermore, the diversity based on the seven STRs carried by O1a* individuals is higher in the Daic speakers than the diversities in Indonesians and Taiwan aborigines (Table 3 ). The population with the highest diversity is not always the oldest, but can also be a result of admixture with other neighbouring populations. However, the high diversity of the $\mathrm{O} 1 \mathrm{a}^{*}$ haplogroup of the Daic speakers should have resulted from the oldest age of the population, as this haplogroup is almost absent in the neighbouring populations and no admixture can bring more diversity. Taking the results of diversity and divergence together, the Daic population group is likely the ancestral group from which the Indonesians and Taiwan aborigines derived separately in paternal lineages. Other haplogroups of $\mathrm{Y}$ chromosomes (e.g. O3-M122, O2aM95) displayed a similar pattern as O1a*, showing that the Daic group is genetically closer to Indonesians and Taiwan aborigines than these latter two groups are to each other (Table 3). Interestingly, O2a may be traced even further to Austro-Asiatic populations as suggested by a recent study [38].

A median-joining network was constructed based on 7 -

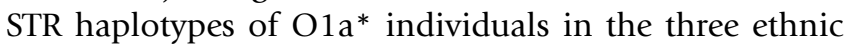
groups (Figure 3). If THH of ISEA is true, i.e., ISEA primarily derived from Taiwan aborigines, one would expect sharing and/or connections of ISEA lineages and Taiwan aboriginal lineages in the network. In Figure 3, Daic lineages (green nodes) constitute the center of the network. All ISEA lineages (yellow nodes) and Taiwan aboriginal 
Table I: Classification, population, and location information of the populations sampled in this study

\begin{tabular}{|c|c|c|c|c|c|c|c|c|c|}
\hline No. & ETHNIC & ISO639-3 & FAMILY & SUB-FAMILY & BRANCH & POPULATION & COUNTRY & PROVINCE & COUNTY \\
\hline DI & Bolyu & ply & Austro-Asiatic & Mon-Khmer & Palyu & 10,000 & China & Guangxi & Longlin \\
\hline D2 & Yerong & yrn & Daic & Kadai & Bu-Rong & 400 & China & Guangxi & Napo \\
\hline D3 & Qau & gio & Daic & Kadai & Ge-Chi & 3,000 & China & Guizhou & Bijie \\
\hline D4 & Blue-Gelao & giq & Daic & Kadai & Ge-Chi & 1,700 & China & Guangxi & Longlin \\
\hline D5 & Lachi & lbt & Daic & Kadai & Ge-Chi & 9,016 & China & Yunnan & Maguan \\
\hline D6 & Mollao & & Daic & Kadai & Ge-Chi & 30,000 & China & Guizhou & Majiang \\
\hline D7 & Red-Gelao & gir & Daic & Kadai & Ge-Chi & 1,500 & China & Guizhou & Dafang \\
\hline D8 & White-Gelao & giw & Daic & Kadai & Ge-Chi & 1,200 & China & Yunnan & Malipo \\
\hline D9 & Hlai-Qi & lic & Daic & Kadai & Hlai & 747,000 & China & Hainan & Tongza \\
\hline DIO & Jiamao & jio & Daic & Kadai & Hlai & 52,300 & China & Hainan & Baoting \\
\hline DII & Buyang & byu & Daic & Kadai & Yang-Biao & 3,000 & China & Yunnan & Guangnan \\
\hline DI2 & Cun & cuq & Daic & Kadai & Yang-Biao & 70,000 & China & Hainan & Dongfang \\
\hline DI3 & Laqua & laq & Daic & Kadai & Yang-Biao & 307 & China & Yunnan & Malipo \\
\hline DI4 & Man-Caolan & $\mathrm{mlc}$ & Daic & Kam-Tai & Be-Tai & 114,000 & China & Guangxi & Fangcheng \\
\hline DI5 & Zhuang-N & $\operatorname{ccx}$ & Daic & Kam-Tai & Be-Tai & $10,000,000$ & China & Guangxi & Wuming \\
\hline DI6 & Zhuang-S & ccy & Daic & Kam-Tai & Be-Tai & $4,000,000$ & China & Guangxi & Chongzuo \\
\hline DI7 & Lingao & onb & Daic & Kam-Tai & Be-Tai & 520,000 & China & Hainan & Lingao \\
\hline D18 & $\mathrm{E}$ & eee & Daic & Kam-Tai & Be-Tai & 30,000 & China & Guangxi & Rongshui \\
\hline D19 & Ai-Cham & aih & Daic & Kam-Tai & Kam-Sui & 2,300 & China & Guizhou & Libo \\
\hline D20 & Dong/Kam & doc & Daic & Kam-Tai & Kam-Sui & 907,560 & China & Guangxi & Sanjiang \\
\hline D2I & Sui & swi & Daic & Kam-Tai & Kam-Sui & 345,993 & China & Guangxi & Rongshui \\
\hline D22 & Mak & $\mathrm{mkg}$ & Daic & Kam-Tai & Kam-Sui & 10,000 & China & Guizhou & Libo \\
\hline D23 & Mulam & $\mathrm{mlm}$ & Daic & Kam-Tai & Kam-Sui & 159,328 & China & Guangxi & Luocheng \\
\hline D24 & Maonan & $\mathrm{mmd}$ & Daic & Kam-Tai & Kam-Sui & 37,000 & China & Guangxi & Huanjiang \\
\hline D25 & Biao & byk & Daic & Kam-Tai & Kam-Sui & 20,000 & China & Guangdong & Huaiji \\
\hline D26 & Then & tct & Daic & Kam-Tai & Kam-Sui & 20,000 & China & Guizhou & Pingtang \\
\hline D27 & Danga & & Daic & Unclassified & & $1,000,000$ & China & Hainan & Lingshui \\
\hline D28 & DornQdayc & & Daic & Unclassified & & 500,000 & China & Shanghai & Minhang \\
\hline D29 & CaoMiao & cov & Daic & Kam-Tai & Kam-Sui & 63,632 & China & Guangxi & Rongshui \\
\hline D30 & Laka & $\mathrm{lbc}$ & Daic & Kam-Tai & Kam-Sui & 12,000 & China & Guangxi & Jinxiu \\
\hline TI & Amis & ami & Austronesian & Taiwan & Paiwanic & 130,000 & China & Taiwan & Hualien \\
\hline $\mathrm{T} 2$ & Pazeh & uun & Austronesian & Taiwan & Paiwanic & 300 & China & Taiwan & Cholan \\
\hline T3 & Siraiya-Makatao & fos & Austronesian & Taiwan & Paiwanic & 10,000 & China & Taiwan & Hualien \\
\hline $\mathrm{T} 4$ & Thao & ssf & Austronesian & Taiwan & Paiwanic & 248 & China & Taiwan & Nantou \\
\hline T5 & Paiwan & pwn & Austronesian & Taiwan & Paiwanic & 53,000 & China & Taiwan & Taitung \\
\hline $\mathrm{T} 6$ & Atayal & tay & Austronesian & Taiwan & Atayalic & 63,000 & China & Taiwan & Yilan \\
\hline $\mathrm{T7}$ & Rukai & dru & Austronesian & Taiwan & Paiwanic & 8,007 & China & Taiwan & Pingtung \\
\hline $\mathrm{T} 8$ & Pyuma & pyu & Austronesian & Taiwan & Paiwanic & 8,132 & China & Taiwan & Taitung \\
\hline T9 & Tsou & tsu & Austronesian & Taiwan & Tsouic & 5,797 & China & Taiwan & Kagi \\
\hline TIO & Bunun & bnn & Austronesian & Taiwan & Paiwanic & 34,000 & China & Taiwan & Hualien \\
\hline TII & Saisiyat & xsy & Austronesian & Taiwan & Paiwanic & 4,194 & China & Taiwan & Yilan \\
\hline II & Batak & $\mathrm{bbc}$ & Austronesian & Malayo-Polynesian & Western & $5,800,000$ & Indonesia & Sumatera Utara & \\
\hline 12 & Bangka & mly & Austronesian & Malayo-Polynesian & Western & 500,000 & Indonesia & Sumatera Selatan & Bangka \\
\hline 13 & Malay (Riau) & mly & Austronesian & Malayo-Polynesian & Western & $2,000,000$ & Indonesia & Riau & \\
\hline 14 & Minangkabau & $\min$ & Austronesian & Malayo-Polynesian & Western & $4,000,000$ & Indonesia & Sumatera Barat & \\
\hline 15 & Palembang & plm & Austronesian & Malayo-Polynesian & Western & $1,100,000$ & Indonesia & Sumatera Selatan & \\
\hline 16 & Nias & nia & Austronesian & Malayo-Polynesian & Western & 600,000 & Indonesia & Sumatera Utara & Nias \\
\hline 17 & Dayak & dyk & Austronesian & Malayo-Polynesian & Western & $2,100,000$ & Indonesia & Kalimantan Tengah & \\
\hline 18 & Banjar & bjn & Austronesian & Malayo-Polynesian & Western & $3,000,000$ & Indonesia & Kalimantan Selatan & \\
\hline 19 & Javanese & jav & Austronesian & Malayo-Polynesian & Western & $75,500,000$ & Indonesia & Jawa Tengah & \\
\hline 110 & Tengger & tes & Austronesian & Malayo-Polynesian & Western & 500,000 & Indonesia & Jawa Timur & \\
\hline III & Balinese & ban & Austronesian & Malayo-Polynesian & Western & $3,800,000$ & Indonesia & Bali & \\
\hline 112 & Bugis & bug & Austronesian & Malayo-Polynesian & Western & $3,500,000$ & Indonesia & Sulawesi Selatan & \\
\hline 113 & Toraja & sda & Austronesian & Malayo-Polynesian & Western & 500,000 & Indonesia & Sulawesi Selatan & \\
\hline 114 & Makasar & mak & Austronesian & Malayo-Polynesian & Western & $1,600,000$ & Indonesia & Sulawesi Selatan & \\
\hline 115 & Minahasa & tom & Austronesian & Malayo-Polynesian & Western & 200,000 & Indonesia & Sulawesi Utara & \\
\hline 116 & Kaili & lew & Austronesian & Malayo-Polynesian & Western & 471,000 & Indonesia & Sulawesi Tengah & \\
\hline 117 & Sasak & sas & Austronesian & Malayo-Polynesian & Western & $2,100,000$ & Indonesia & Nusa Tenggara Barat & Lombok \\
\hline 118 & Sumbawa & smw & Austronesian & Malayo-Polynesian & Western & 400,000 & Indonesia & Nusa Tenggara Barat & Sumbawa \\
\hline 119 & Sumba & $\mathrm{xbr}$ & Austronesian & Malayo-Polynesian & Central & 234,574 & Indonesia & Nusa Tenggara Timur & Sumba \\
\hline 120 & Alor & aol & Austronesian & Malayo-Polynesian & Central & 25,000 & Indonesia & Nusa Tenggara Timur & Alor \\
\hline 121 & Irian & & Geelvink Bay & & & 20,806 & Indonesia & Irian Jaya & \\
\hline 122 & Cham & cjm & Austronesian & Malayo-Polynesian & Western & 99,000 & Vietnam & Binhdinh & \\
\hline 123 & Tsat & huq & Austronesian & Malayo-Polynesian & Western & 4,500 & China & Hainan & Sanya \\
\hline
\end{tabular}


Table 2: Y-SNP haplogroup frequencies of the newly studied samples (\%)

\begin{tabular}{|c|c|c|c|c|c|c|c|c|c|c|c|c|c|c|c|c|c|c|}
\hline Population & Size & C & D* & DI & $\mathbf{F}$ & $\mathbf{M}$ & $\mathbf{K}$ & O* & Ola* & Ola2 & $02 a^{*}$ & O2al & O3* & O3al & $03 a 4$ & $03 a 5$ & $03 a 5 a$ & $\mathbf{P}$ \\
\hline Bolyu & 30 & & 3.3 & & & & 3.3 & 10.0 & 10.0 & 3.3 & 23.3 & & 30.0 & & & 6.7 & 10.0 & \\
\hline Yerong & 16 & & & & & & & & & & 62.5 & 6.3 & 18.8 & & & 12.5 & & \\
\hline Qau & 13 & & 15.4 & & & & 7.7 & 23.1 & & & 15.4 & & 30.8 & & & & 7.7 & \\
\hline Blue Gelao & 30 & & & & & & 3.3 & 13.3 & 60.0 & & 16.7 & & 3.3 & & & 3.3 & & \\
\hline Lachi & 30 & 3.3 & & 3.3 & 13.3 & & 13.3 & 16.7 & 6.7 & & 10.0 & & 3.3 & & & 6.7 & 23.3 & \\
\hline Mollao & 30 & 10.0 & & & & & 3.3 & 13.3 & 3.3 & 3.3 & 63.3 & & 3.3 & & & & & \\
\hline Red Gelao & 31 & 3.2 & & & & & 6.5 & 22.6 & 22.6 & & 16.1 & & 12.9 & & & & 16.1 & \\
\hline White Gelao & 14 & & & & & & & 35.7 & 14.3 & & 42.9 & & & & & 7.1 & & \\
\hline Hlai-Qi & 34 & & & & & & & 35.3 & 32.4 & & 29.4 & & & & & & 2.9 & \\
\hline Jiamao & 27 & & & & & & & 25.9 & 51.9 & & 22.2 & & & & & & & \\
\hline Buyang & 32 & & 3.1 & & 6.3 & & 6.3 & 9.4 & 3.1 & & 71.9 & & & & & & & \\
\hline Cun & 31 & 3.2 & & & & & 6.5 & 9.7 & 38.7 & & & & 38.7 & & & & 3.2 & \\
\hline Laqua & 25 & & & & & & & 32.0 & 4.0 & & 60.0 & & & & & 4.0 & & \\
\hline Man-Caolan & 30 & 10.0 & & & & & 10.0 & 53.3 & 3.3 & & 20.0 & & & & & 3.3 & & \\
\hline Zhuang-N & 22 & & & & & & & 13.6 & & 4.6 & 72.7 & & & 4.6 & & & 4.6 & \\
\hline Zhuang-S & 15 & & & & & & & 13.3 & 20.0 & & 60.0 & 6.7 & & & & & & \\
\hline Lingao & 30 & & & & & & 3.3 & 16.7 & 26.7 & & 13.3 & & 3.3 & & & 10.0 & 26.7 & \\
\hline $\mathrm{E}$ & 31 & 3.2 & & & 3.2 & & 9.7 & 16.1 & 6.5 & & 54.8 & & 3.2 & & & 3.2 & & \\
\hline Laka & 23 & 4.4 & 52.2 & & & & 4.4 & & & & 8.7 & & 26.1 & & 4.4 & & & \\
\hline Kam/Dong & 38 & 21.1 & & & & & 5.3 & 10.5 & & & 39.5 & & 10.5 & & & 2.6 & 10.5 & \\
\hline Sui & 50 & & & & 8.0 & & 10.0 & & 18.0 & & 44.0 & & & & & 20.0 & & \\
\hline Mak\&AiCham & 40 & & & & & & 2.5 & & & & 87.5 & & 5.0 & & & 2.5 & & 2.5 \\
\hline Mulam & 40 & 2.5 & & 12.5 & 7.5 & & 5.0 & & 5.0 & 25.0 & 30.0 & & 7.5 & & & 5.0 & & \\
\hline Maonan & 32 & 9.4 & & & 9.4 & & 15.6 & & & & 56.3 & & 9.4 & & & & & \\
\hline Biao & 34 & 2.9 & & & & & & 5.9 & 14.7 & & 17.7 & & 52.9 & & & & & 5.9 \\
\hline Then & 30 & & 3.3 & & & & & 3.3 & 33.3 & & 50.0 & & & & & & 6.7 & 3.3 \\
\hline Danga & 40 & 20.0 & 5.0 & & 2.5 & & 7.5 & 17.5 & 7.5 & 5.0 & 17.5 & & & & & 2.5 & 15.0 & \\
\hline DornQdayc-S & 74 & 2.1 & & 6.3 & & & & & 39.6 & 12.5 & 8.3 & & 4.2 & & & 27.1 & & \\
\hline DornQdayc-N & 51 & 5.9 & 2.0 & & & & 2.0 & 31.4 & 29.4 & & 2.0 & & 2.0 & & & 11.8 & 13.7 & \\
\hline CaoMiao & 33 & & & & & & 8.2 & & 10.0 & & 3.0 & & 66.7 & & & 12.1 & & \\
\hline Amis & 28 & & & & & & & 7.1 & 42.8 & 17.8 & 7.1 & & 21.4 & & & 3.6 & & \\
\hline Pazeh & 21 & & & & & & 14.3 & & 38.1 & 19.1 & 14.3 & & 14.3 & & & & & \\
\hline Makatao & 37 & 2.7 & & & & & 2.7 & 5.4 & 70.3 & & 5.4 & & & & & 13.5 & & \\
\hline Thao & 22 & & & & & & 4.6 & & 81.8 & 4.6 & & & 9.1 & & & & & \\
\hline Paiwan & 22 & & & & & & & & 63.6 & 27.3 & & & & & & 9.1 & & \\
\hline Atayal & 22 & & & & & & & & 95.5 & & & & 4.5 & & & & & \\
\hline Rukai & 11 & & & & & & & & 81.8 & 18.2 & & & & & & & & \\
\hline Pyuma & 11 & & & & & & & & 72.7 & 9.1 & & & 9.1 & & & & & 9.1 \\
\hline Tsou & 18 & & & & & & & & 88.9 & 5.6 & & & 5.6 & & & & & \\
\hline Bunun & 17 & & & & & & 5.9 & & 17.6 & 58.8 & & 17.6 & & & & & & \\
\hline Saisiyat & 11 & & & & & & & & 45.5 & 9.1 & 9.1 & 9.1 & 27.3 & & & & & \\
\hline Batak & 13 & & & & & & 11.6 & 19.3 & 23.1 & & 15.4 & & 23.1 & & & & & 7.7 \\
\hline Bangka & 13 & 7.7 & & & & & 7.7 & & 30.8 & & 23.1 & & 23.1 & & 7.7 & & & \\
\hline Malay & 13 & & & & 7.7 & & 7.7 & 7.7 & 38.5 & & 7.7 & & 23.1 & & & & & 7.7 \\
\hline Minangkabau & 15 & & & & 6.7 & & 20.0 & 20.0 & & & 13.3 & & 20.0 & & & & & 20.0 \\
\hline Palembang & 11 & 9.1 & & & & & & & 63.6 & & 18.2 & & 9.1 & & & & & \\
\hline Nias & 12 & & & & & & & & & & & 8.3 & 91.7 & & & & & \\
\hline Dayak & 15 & & & & 6.7 & & 26.7 & & 20.0 & 20.0 & 6.7 & 6.7 & 13.3 & & & & & \\
\hline Banjar & 15 & 13.3 & & & 6.7 & & & & 26.7 & & 26.7 & & 26.7 & & & & & \\
\hline Javanese & 15 & & & & & & 26.7 & 26.7 & 20.0 & & 13.3 & & 13.3 & & & & & \\
\hline Tengger & 12 & 16.7 & & & & & 8.3 & & 33.3 & & 33.3 & & & & 8.3 & & & \\
\hline Balinese & 14 & & & & & & 28.6 & 14.3 & 7.1 & & 28.6 & & 14.3 & & 7.1 & & & \\
\hline Bugis & 15 & & & & 13.3 & & 20.0 & & 33.3 & & & & 26.7 & & & & 6.7 & \\
\hline Torajan & 15 & & & & 13.3 & & 13.3 & 13.3 & 13.3 & 6.7 & 33.3 & & & & 6.7 & & & \\
\hline Minahasa & 14 & & & & & 7.1 & 50.0 & & 21.4 & & 7.1 & & 14.3 & & & & & \\
\hline Makassar & 13 & 23.1 & & & & & & & 30.8 & 15.4 & 7.7 & & 23.1 & & & & & \\
\hline Kaili & 15 & 6.7 & & & & & 33.3 & & 20.0 & & 6.7 & & 26.7 & & & & & 6.7 \\
\hline Sasak & 15 & 13.3 & & & & & 13.3 & 26.7 & 6.7 & & 20.0 & & 20.0 & & & & & \\
\hline Sumbawa & 18 & & & & & & 16.7 & & & & & & 83.3 & & & & & \\
\hline Sumba & 14 & & & & 14.3 & & 78.6 & & & & & & 7.1 & & & & & \\
\hline Alor & 13 & 38.5 & & & & & 30.7 & & & & & & 23.1 & & & & & 7.7 \\
\hline Irian & 11 & 45.5 & & & & 36.4 & 18.2 & & & & & & & & & & & \\
\hline Cham & 11 & & & & & & & 9.1 & 90.9 & & & & & & & & & \\
\hline Tsat & 31 & 12.9 & & & & & & 16.1 & 58.1 & & 3.2 & & & & & 6.5 & 3.2 & \\
\hline
\end{tabular}

Zhuang and DornQdayc are divided into Southern $(\mathrm{S})$ and Northern $(\mathrm{N})$ parts. 

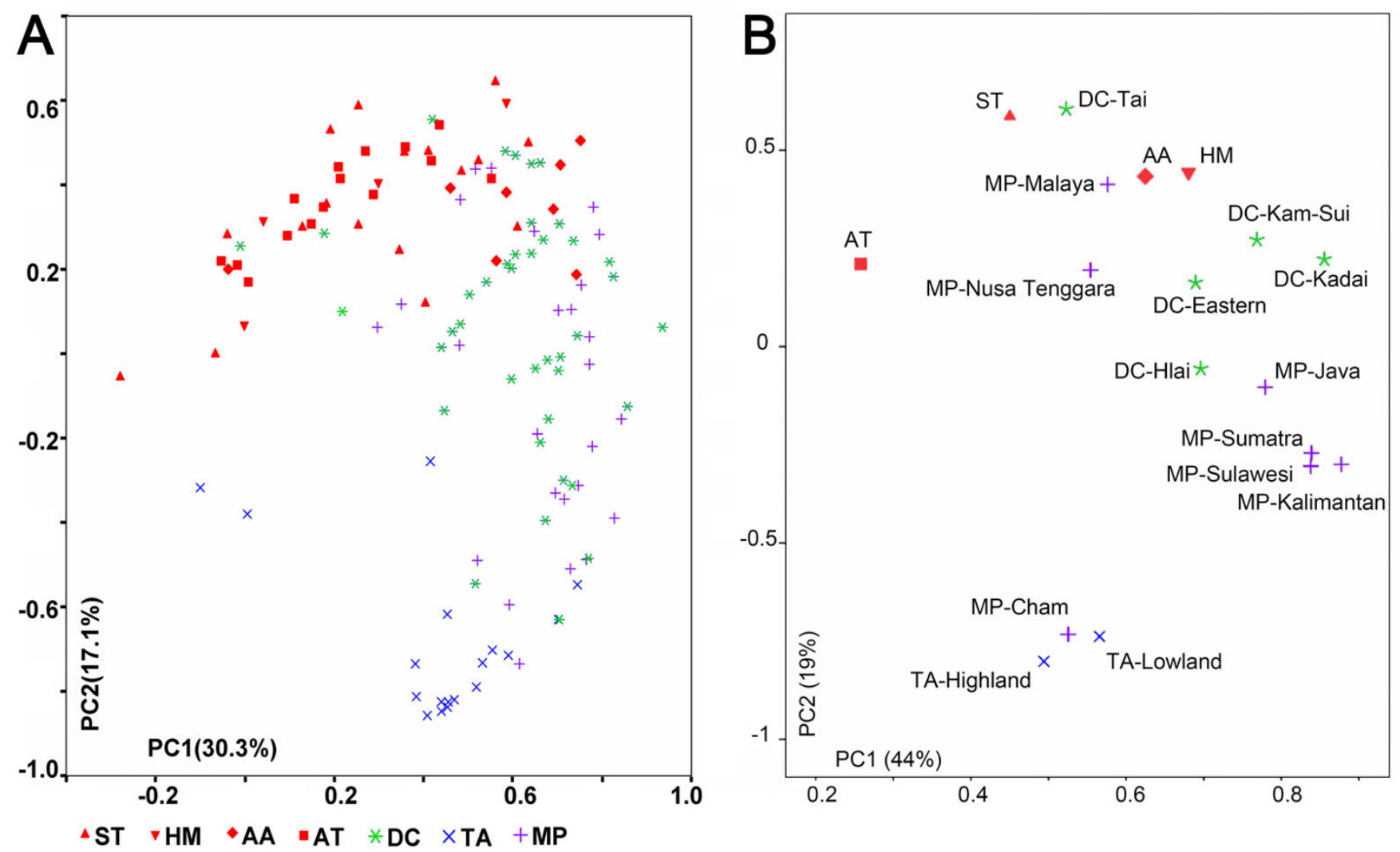

\section{Figure 2}

Principal component plot of Y-SNP. (A) PC plot of all the population samples. DC (green stars) is closest to MP (purple crosses) and TA (blue crosses). All of the other groups including ST, HM, AA, and AT (red spots including triangles, squares and diamonds) are rather far removed from MP and TA, which indicates that $D C$ is the only group that might be related to MP and TA. (B) PC plots of pooled samples. The ST, HM, AA, and AT samples were pooled according to the linguistic families. The DC samples were pooled according to the sub-families. MP and TA samples were pooled according to the geographic locations. Ethnic groups: AA, Austro-Asiatic speakers; AT, Altaic speakers; DC, Daic speakers; HM, Hmong-Mien speakers; MP, Malayo-Polynesian speakers; ST, Sino-Tibetan speakers; TA, Taiwan aborigines.

lineages (blue nodes) are either shared or connected to one of the Daic lineages, either directly or indirectly. In contrast, none of the Taiwan aboriginal lineages (except for one) are shared with or connected to the ISEA lineages. These observations suggest that ISEA did not directly derive from Taiwan aborigines but that the ISEA and Taiwan aborigines derived from the Daic independently of each other.

We further noticed the Daic lineages that are connected to ISEA lineages in the network. Interestingly, most of the Daic haplotypes connecting to the ISEA are either from Hainan Island or from Guangxi, which is to northwest of Hainan (green nodes with dark green frames in Figure 3). These Hainan and Guangxi populations are located around the Gulf of Tonkin. In particular, Cham, a MalayoPolynesian population in South Vietnam, as well as Tsat in Hainan, which is a subgroup of Cham $[11,39]$, were found to connect Daic and Indonesians in the network.
Therefore, we hypothesized that the ISEA likely originated in the area around the Gulf of Tonkin, and migrated southward through the Indochina Peninsula to the Malaya Peninsula before they spread to most of the islands of the Pacific Ocean and the Indian Ocean.

The age of the O1a* haplogroup was estimated in the network. The total age is $33765 \pm 5221$ years, which corresponds to the last Ice Age. The age of all the Daic samples in the network is $33193 \pm 5577$ years, close to the age of O1a*. It is not easy to estimate the real age of the Taiwan clusters as they overlap with the Daic haplotypes to a large extent. This kind of overlap also indicates multiple migrations from Daic populations to Taiwan aborigines. We estimated the age of the Taiwan cluster in the left side of the network to be $14659 \pm 3110$ years. The estimated age of all the Taiwan samples is $21268 \pm 3148$ years. Interestingly, this latter age is close to the age of the oldest human remains found in Taiwan, those of the Chochen Man [40]. 
Table 3: Y-STR diversity of O Ia, O2a, and 03 haplogroup

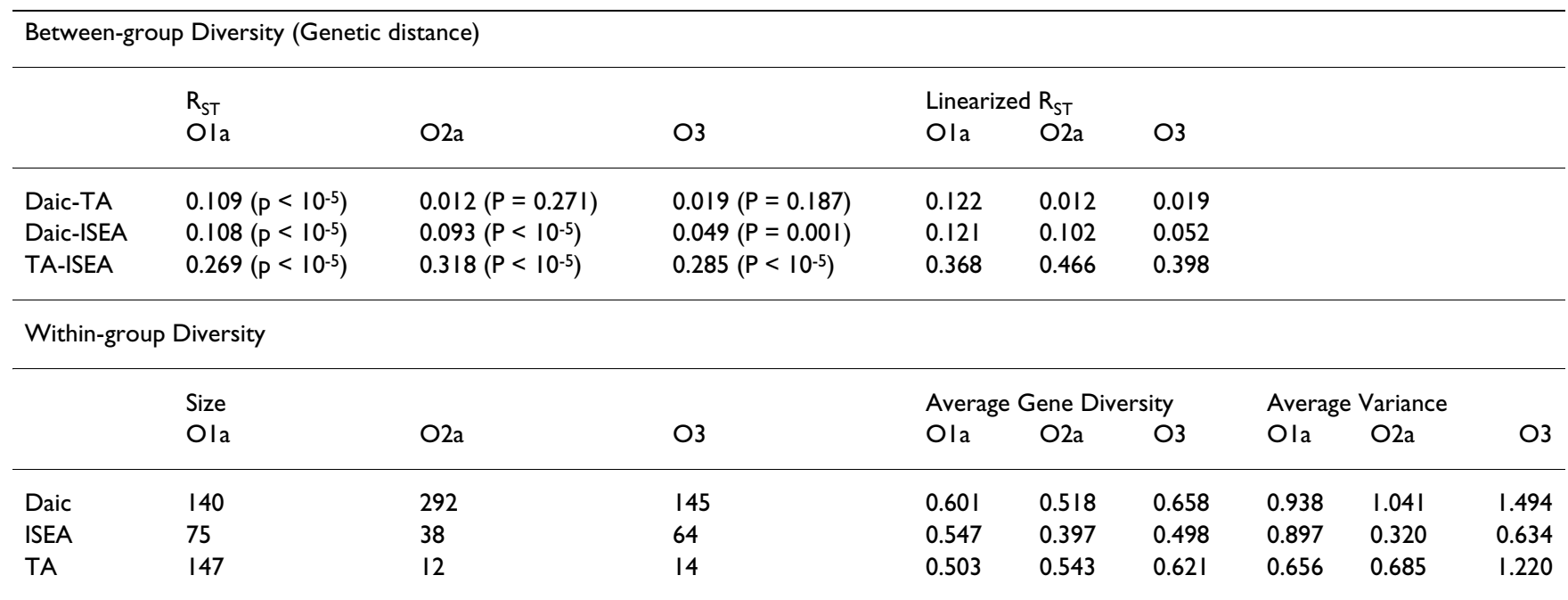

Y STR genetic distances between Taiwan Aborigines (TA) and ISEA were always largest and more than twice as much as those between Daic and one of the TA and ISEA groups among the samples of all of the three haplogroups, Ola, O2a and O3. Two statistics of $R_{s t}$ and Linearized $R_{s t}$ referred to reference [53].

Y STR within-group gene diversities of Daic were always largest. Average gene diversity refers to reference [55], and variance refers to reference [56].

Therefore, we conclude that the migration of $\mathrm{O}_{1} \mathrm{a}^{*}$ individuals from the mainland to Taiwan Island occurred during the Palaeolithic Age.

Because two fairly specific clusters of ISEA haplotypes can be observed in the network, we performed time estimates in both clusters. The age of the left ISEA cluster in the network is $9895 \pm 2393$ years, whereas that of the right cluster is $25880 \pm 7137$ years. The linguistic estimate for the origin of the Malayo-Polynesian is younger than that of our estimates, around 5000-6000 years ago [16]. Moreover, little overlap between Daic haplotypes and ISEA haplotypes is observed in the network, which indicates bottleneck effects might have formed the two ISEA clusters during the emigration of ISEA populations out of the ancestral Daic populations. Geographically, the bottleneck might be the narrow seashore of Vietnam. Therefore, the O1a* haplogroup was most probably introduced into ISEA populations during the origin of the Malayo-Polynesians more than 7500 years ago. However, the possibility of recent migrations of the O1a individuals into ISEA can not be ignored, because the genetic time estimate is not precise enough to eliminate such a possibility.

It should be noted that, in the Express Train Hypothesis, there are two different aspects: 1) the origin of the migrations, i.e. the Taiwan Homeland Hypothesis, and 2) the mode of migrations, i.e., a rapid dispersal starting from Indonesia. In this study, we examined the THH in Western Austronesians by including the Daic speakers and ISEA, both of which are largely missing in previous studies. We show that Taiwan is not likely the homeland of Indone- sian ISEA, at least not for the major paternal lineages. Although both Taiwan aborigines and Indonesian ISEA derived from the Daic, their departures occurred separately, suggesting that the major paternal lineages of Western Austronesian populations are not monophyletic.

Interestingly, the spread of the domestic pig in the Southeast Asia archipelago and the Pacific took place in almost the same way as that of Western Austronesian populations suggested by our study. The pigs in Taiwan and in regions as far as Micronesia came directly from the mainland of East Asia, while those in the Southeast Asian archipelago and Polynesia came from the Indochina Peninsula. It is assumed that the domestic pig was introduced by human populations during early migrations, which would imply that humans have also entered the Southeast Asia archipelago and the Pacific in two different routes [41].

In fact, our observations are consistent with a monophyletic Austro-Tai super-phylum which contains Daic speakers, Malayo-Polynesians, and Taiwan aborigines [5]. The observations presented in this study demonstrate that it is absolutely necessary to include Daic populations and ISEA in the Austronesian origin studies. Without these groups, Polynesians and Taiwan aborigines would have appeared most similar to each other, leading to the conclusion that all the Austronesians originated in Taiwan.

Our results suggest that the Gulf of Tonkin is more likely the homeland of the paternal lineages of ISEA. Due to the complex nature of population migrations from Eastern Indonesia to the Pacific Islands [23,42-47], and the pro- 


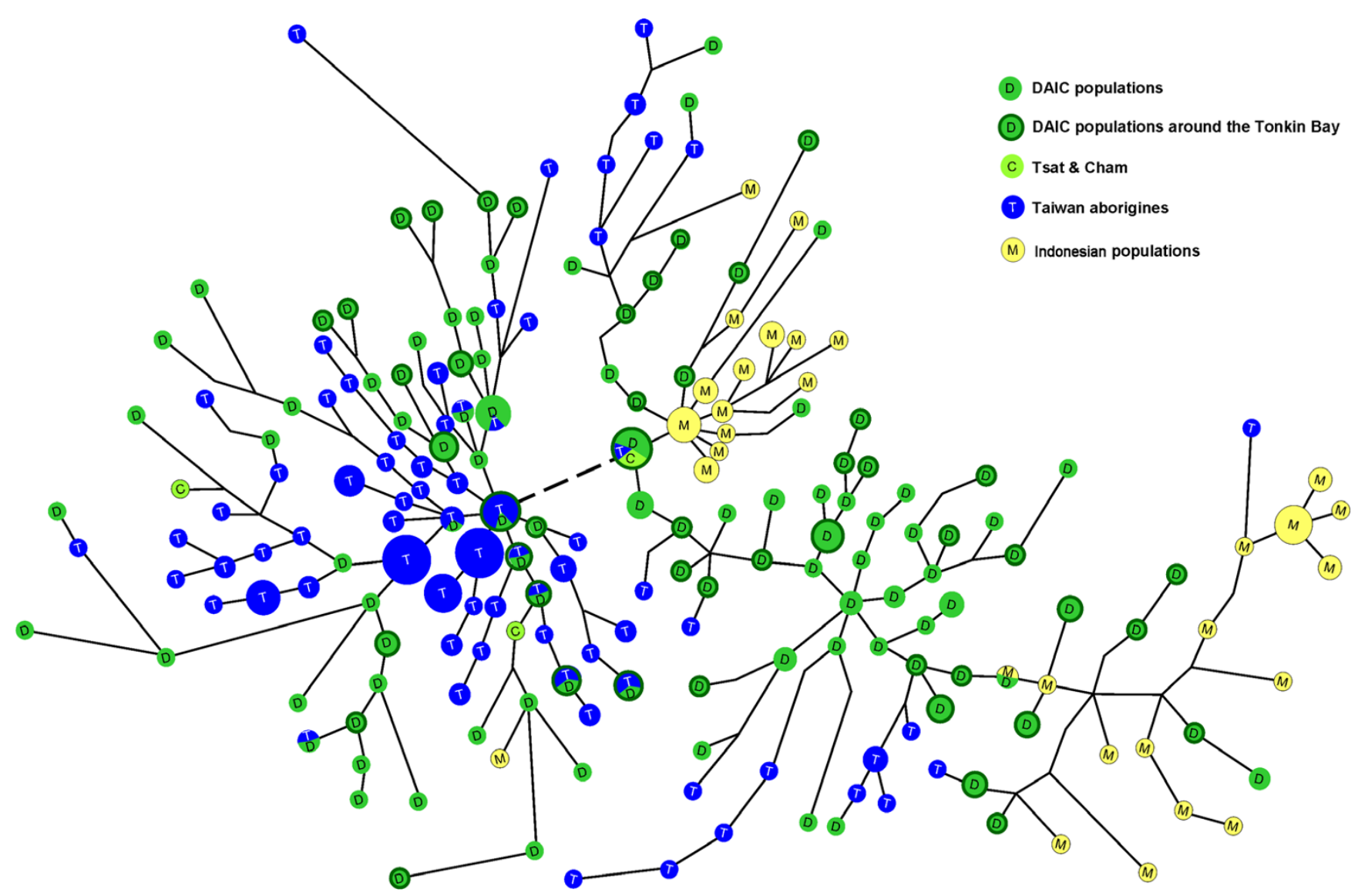

Figure 3

Haplotype network of Y-STRs of Haplogroup O Ia* individuals. As the original network was too complicated to display, here we presented the shortest tree of the largest possibility reduced from the network (this function is available in the recent versions of NETWORK program). Each node represents an O Ia* STR haplotype. The lengths of the lines are proportional to the mutation steps. The broken line stands for only one step. The sizes of the nodes are proportional to their frequencies. Almost none of the ISEA haplotypes is directly linked to Taiwan aborigines, and both ISEA and Taiwanese are linked directly or indirectly to the Daic haplotypes holding the centre of the network (big green node).

nounced genetic division between Eastern and Western Austronesians [27], we opted not to include Polynesian data in our analysis. Instead, we only analyzed Western Austronesians. The absence of O1a-M119 in Polynesian populations is intriguing and it can not be simply explained by invoking the bottleneck effect [21-25] given that a great deal of diversity of Y chromosome haplotypes has been observed in Polynesians [23,42].

Consistent with our findings for paternal lineages, mitochondrial DNA studies on populations from Peninsular Malaysia also suggest an ancestry of aboriginal Malays in Indochina around the time of the Last Glacial Maximum [48]. This ancestry subsequently dispersed through the Malaya Peninsula into island Southeast Asia [48]. The ISEA mtDNA studies also indicated that if an Austronesian migration from Taiwan did take place, it was demographically minor [49].
Most of our conclusions are based on the analysis of O1a*, which is only a fraction of the Y-chromosome lineages found in these populations. The frequency of this group of lineages is remarkable in Taiwanese populations, but it is not so dramatic in Malayo-Polynesians or Daic populations. It is possible that some population events could have involved other Y-chromosome lineages. It is also reasonable that there are other minor parts of paternal lineages with different origins, such as aboriginal populations of Indonesia prior to the formation of Austronesian, or that more recent migrations from South Asia took place [29]. The genetic relationship amongst the East and Southeast Asians are much more complicated than expected.

\section{Conclusion}

Our results show that the Daic populations are closer to the Western Austronesian populations in paternal line- 
ages than any other ethnic groups in East Asia are. The STR diversity of the Y chromosome haplogroup O1a-M119, the major haplogroup among the Daic and Western Austronesian populations, shows that Taiwan and ISEA, two groups of Western Austronesian, derived from the Daic independently of each other. Therefore, it is most likely that the ISEA populations mainly originated in the region around the Tonkin Gulf, the homeland of the Daic, and migrated to Indonesia through the Vietnam corridor. In contrast, the Taiwan aborigines migrated from mainland China directly. Our results indicate that a super-phylum, which includes Taiwan aborigines, Daic, and MalayoPolynesians, is genetically educible.

\section{Methods \\ Sampling}

Blood samples from 30 Daic populations across South China were collected using FTA cards (Whatman ${ }^{\circledR}$ Inc), covering almost all of the Daic populations in China. Those from 11 Taiwan aborigine populations were collected from both the lowlands and the highlands of Taiwan. Samples from 23 Malayo-Polynesian populations were collected, among which 21 were collected across Indonesia, 1 from Binhdinh of Vietnam, and 1 from Hainan of China. The sample sizes from each population are given in Table 2. All of the 1,509 individuals studied from these populations are unrelated and gave their consents for this study. Individual samples were from diverse regions of the population distribution area to make the sample more diverse. Reference data for 70 other groups in East and Southeast Asia were obtained from the literature (including some Daic speaking populations [23], Malayo-Polynesians [23], Taiwan aborigines [23], TibetoBurman speaking populations [31-33], Han Chinese [31,34], and Altaic speaking populations [31]), for a total reference sample size of 1,348 individuals. In PC analysis, these samples refer to a total of 134 different population groups, including newly typed and previously published populations.

Although the sample sizes of some populations were relatively small, we do not think it is necessary to enlarge these sample sizes, as they were collected from very small populations with low Y chromosome diversity, such as the Ai-Cham and Geelvink Irians. The effective population size of the Y chromosome is usually less than one fourth of the size of that of autosomes. Therefore, Y chromosome diversity studies require much smaller sample sizes than studies of autosomal genetic markers. For a normal size population of some hundred thousand, a sample of around 30 individuals will be sufficient. Even fewer samples are required for small populations. Here we maintained a sample size of around 30 for most of the populations, and around 15 for small populations.

\section{Genetic markers}

Twenty bi-allelic Y-chromosome markers (SNP), YAP, M15, M130, M89, M9, M5, M122, M134, M7, M117, M121, M111, M17, M175, M119, M110, M95, M88, M45, and M120 were typed by PCR-based restriction-fragment length polymorphism methods [31]. Most of these markers are highly informative in East Asians and define 19 haplogroups following the Y Chromosome Consortium nomenclature [50].

Seven microsatellite markers (STR) on Y-chromosome, DYS19, DYS388, DYS389-1, DYS390, DYS391, DYS392, and DYS393 were typed using fluorescent-labelled primers [51]. The genotyping results are given in Additional file 2.

\section{Data analysis}

Population relationships were investigated with principal component analyses using Y-chromosome haplogroup frequencies and SPSS11.0 software (SPSS Inc.). Some of the SNPs, such as M175 and M117, were not typed for the previously published populations, therefore our $\mathrm{O}^{*}$ M175 data were combined into haplogroup $\mathrm{K}$, and O3a5a-M117 into O3a5* in our PC analysis. Correlation analysis among haplogroups and PCs was also conducted using SPSS11.0.

The admixture analysis was performed using an ADMIX 2.0 program [52] in order to evaluate the genetic influence of Han Chinese on the Daic populations. We assumed the potential admixture started 2,500 ago when the Qin army entered the Daic area in Canton. The admixture proportions of the Indonesians were also estimated by ADMIX 2.0, and the admixture history was to start 5,000 years ago.

The genetic distances among Daic, Taiwan aborigines, and Malayo-Polynesians were estimated by $\mathrm{R}_{\mathrm{ST}}$ and linearized $\mathrm{R}_{\mathrm{ST}}$ [53] using ARLEQUIN software [54], and the diversities of three groups were evaluated by average gene diversity, haplotype diversity [55], and variance of the STR allele sizes [56].

A Median-Joining network of O1a* STR haplogroups was drawn by Network 4.1 software (Fluxus Technology Ltd). The age of $\mathrm{O} 1 \mathrm{a}$ * was estimated in the network. The mutation rate used in the time estimate is $1.932 \times 10^{-4}$ per year, the sum of the mutation rates [57] of all the STRs used in the network. We assumed 25 years for one generation.

\section{Authors' contributions}

HL, SJC, BS, YL, PP, ZQ, WL, XC, XL, and NY carried out the molecular genetic studies. HL and LJ drafted the manuscript. HL, BW, DL, MH, RD, SM, CCT, and LJ participated in the design of the study and performed the 
statistical analysis. HL, SJC, PP, SP, and DT collected the samples. All authors read and approved the final manuscript.

\section{Additional material}

\section{Additional file 1}

Correlation coefficients between haplogroups and PCs. Although P values of the correlation coefficients between PC1 and M9, M110, M95, M88 etc. are all very significant, all of these correlation coefficients are less than 0.5. Thus, PC1 has little information about the ethnic clustering. In contrast, PC2 is significantly correlated with O1a-M119 seen in a large correlation coefficient. This haplogroup distinguishes the Daic-MP-TW cluster. Thus, PC2 provides information on ethnic clustering. Click here for file [http://www.biomedcentral.com/content/supplementary/14712148-8-146-S1.doc]

\section{Additional file 2}

Y-STR haplotypes of individual samples. The names of the individuals begin with ISO639-3 codes of their populations.

Click here for file

[http://www.biomedcentral.com/content/supplementary/14712148-8-146-S2.xls]

\section{Acknowledgements}

We thank all of the donors for making this work possible. Ethnic Affairs Committee of Guangxi Zhuang Autonomous Region, Institute of Ethnology in Guizhou, Xishuangbanna Prefecture Committee of C. C. Youth League, Wenshan Prefecture Committee of C. C. Youth League, Research Society of Hainan Ancient Migrants, Prof. Xingqiu Huang from Guangxi University for Nationalities, and Prof. Shi Shi from Chongqing Teacher's University offered help in sample collection. Prof. Kenneth K. Kidd of Yale University gave important suggestions on the analyses and other techniques. Dr. Angelika Hofmann of Yale University revised the paper and gave important suggestions on the scientific writing. The data collection was supported by NSFC and STCSM to Fudan, a NSF grant to LJ and the Genographic Project.

\section{References}

I. Grimes BF: Ethnologue: Languages of the World Fourteenth Edition Dallas, International Academic Bookstore; 2002

2. Murdock GP: Genetic Classification of the Austronesian Language: A Key to Oceanic Culture History. Ethnology 1964, 3:117-126.

3. Blust R: Subgroup, Circularity and Extinction: Some Issues in Austronesian Comparative Linguistics. Selected Papers from the Eight International Conference on Austronesian Linguistics: 28-30 December 1997, Taipei 1999.

4. Bellwood PA: Mans Conquest of the Pacific: The Prehistory Southeast Asia and Oceania Auckland, Williams Collins Publishers LTD; 1978.

5. Benedict PK: Austro-Thai: Language and Culture Human Relations Area Files Press; 1975.

6. Song SH: Bai-Yue Changchun, Jilin Education Press; 1991.

7. Lin HX: Lin Huixiang's treatise on Anthropology Fuzhou, Fujian People's Press; 198I.

8. Chen QY: Analects of Wu and Yue Cultures (Wu Yue Wenhua Luncong) Beijing, Zhonghua Book Company; 1999.

9. Shaffer LN: Maritime Southeast Asia to $1500 \mathrm{New}$ York, M. E. Sharpe Inc; 1996.

10. Zhang GZ: Archaeology on the coast of Southeast China and origin of Austronesian. In Southern Ethnic Archaeology I Chengdu, Sichuan Univ. Press; 1987.
II. Benedict PK: Austro-Tai Parallel, A Tonal Chamic Language on Hainan. Computational Analyses of Asian and African Languages 1984, 22:83-86.

12. Ni DB: Relationship between Austronesian and Bai-Yue languages. Ethnic Language and Literature 1994, 3:21-35.

13. Meng SM: A Comparative Study on the Historic Period of Dong-Tai Language and Austronesian Family. Guizhou Ethnic Studies 1995, 62:76-91.

14. He P: On the Origin of Ethnic Groups Speaking Austronesian Languages and their Historical Relationship with the Ethnic Groups in South China. Journal of Yunnan University for Nationalities 2003, 20:45-48

15. Wu AQ: Languages and history of Taiwan aborigines: Austronesian history revealed by numerals of Austronesian language. World Nation 2004, 45:68-78.

16. Bellwood PA: Prehistory of the Indo-Malaysian Archipelago Sydney, Academic Press; 1985.

17. Bellwood PA, Fox JJ, Tryon D: The Austronesians: Historical and Comparative Perspectives Canberra, The Australian National University; 1995.

18. Solheim WG II: South-east Asia and Korea from the beginnings of food production to the first states. In The history of humanity Edited by: De Laet SJ. London, Routledge; 1994:468-48I.

19. Oppenheimer SJ, Richards M: Polynesian origins. Slow boat to Melanesia? Nature 200I, 410:166-167.

20. Diamond JM: The express train to Polynesia. Nature 1988 , 336:307-308.

21. Melton T, Peterson R, Redd AJ, Saha N, Sofro AS, Martinson J, Stoneking M: Polynesian genetic affinities with Southeast Asian populations as identified by mtDNA analysis. Am J Hum Genet 1995, 57:403-4I4.

22. Sykes B, Leiboff A, Low-Beer J, Tetzner S, Richards M: The origins of the Polynesians: an interpretation from mitochondrial lineage analysis. Am J Hum Genet 1995, 57: | 463-|475.

23. Su B, Jin L, Underhill P, Martinson J, Saha N, McGarvey ST, Shriver MD, Chu J, Oefner P, Chakraborty R, Deka R: Polynesian origins: insights from the $\mathbf{Y}$ chromosome. Proc Natl Acad Sci USA 2000, 97:8225-8228.

24. Richards M, Oppenheimer S, Sykes B: mtDNA suggests Polynesian origins in Eastern Indonesia. Am J Hum Genet 1998, 63:1234-1236.

25. Lum KJ, Cann RL: mtDNA lineage analyses: origins and migrations of Micronesians and Polynesians. Am J Phys Anthropol 2000, I 13:151-168.

26. Trejaut JA, Kivisild T, Loo JH, Lee CL, He CL, Hsu C], Lee ZY, Lin M: Traces of Archaic Mitochondrial Lineages Persist in Austronesian-Speaking Formosan Populations. PLoS Biol 2005, 3:e247.

27. Shepard EM, Chow RA, Suafo'a E, Addison D, Pérez-Miranda AM, Garcia-Bertrand RL, Herrera RJ: Autosomal STR variation in five Austronesian populations. Hum Biol 2005, 77:825-85I.

28. Kayser M, Lao O, Saar K, Brauer S, Wang X, Nürnberg P, Trent RJ, Stoneking M: Genome-wide Analysis Indicates More Asian than Melanesian Ancestry of Polynesians. Am J Hum Genet 2008, 82(I): 194-198.

29. Karafet TM, Lansing JS, Redd AJ, Reznikova S, Watkins JC, Surata SP, Arthawiguna WA, Mayer L, Bamshad M, Jorde LB, Hammer MF: Balinese $Y$-chromosome perspective on the peopling of Indonesia: genetic contributions from pre-neolithic huntergatherers, Austronesian farmers, and Indian traders. Hum Biol 2005, 77:93-II4.

30. Lansing JS, Cox MP, Downey SS, Gabler BM, Hallmark B, Karafet TM, Norquest P, Schoenfelder JW, Sudoyo H, Watkins JC, Hammer MF: Coevolution of languages and genes on the island of Sumba, eastern Indonesia. Proc Natl Acad Sci USA 2007, 104: $16022-16026$.

3I. Su B, Xiao J, Underhill P, Deka R, Zhang W, Akey J, Huang W, Shen D, Lu D, Luo J, Chu J, Tan J, Shen P, Davis R, Cavalli-Sforza L, Chakraborty R, Xiong M, Du R, Oefner P, Chen Z, Jin L: Y-Chromosome evidence for a northward migration of modern humans into Eastern Asia during the last Ice Age. Am J Hum Genet 1999, 65:1718-1724.

32. Su B, Xiao C, Deka R, Seielstad MT, Kangwanpong D, Xiao J, Lu D, Underhill P, Cavalli-Sforza L, Chakraborty R, Jin L: Y chromosome haplotypes reveal prehistorical migrations to the Himalayas. Hum Genet 2000, 107:582-590.

33. Wen B, Xie X, Gao S, Li H, Shi H, Song X, Qian T, Xiao C, Jin J, Su B, Lu D, Chakraborty R, Jin L: Analyses of Genetic Structure of 
Tibeto-Burman Populations Reveals Sex-Biased Admixture in Southern Tibeto-Burmans. Am J Hum Genet 2004, 74:856-865.

34. Wen B, Li H, Lu D, Song X, Zhang F, He Y, Li F, Gao Y, Mao X, Zhang L, Qian J, Tan J, Jin J, Huang W, Deka R, Su B, Chakraborty R, Jin L: Genetic evidence supports demic diffusion of Han culture. Nature 2004, 43 I:302-305.

35. Li D, Li H, Ou C, Lu Y, Sun Y, Yang B, Qin Z, Zhou Z, Li S, Li J: Paternal Genetic Structure of Hainan Aborigines Isolated at the Entrance to East Asia. PLoS ONE 2008, 3:e2168.

36. Mona S, Tommaseo-Ponzetta M, Brauer S, Sudoyo H, Marzuki S, Kayser M: Patterns of Y-chromosome diversity intersect with the Trans-New Guinea hypothesis. Mol Biol Evol 2007, 24:2546-2555.

37. Kayser M, Brauer S, Weiss G, Schiefenhövel W, Underhill P, Shen P, Oefner P, Tommaseo-Ponzetta M, Stoneking M: Reduced Y-chromosome, but not mitochondrial DNA, diversity in human populations from West New Guinea. Am J Hum Genet 2003, 72:28I-302.

38. Kumar V, Reddy AN, Babu JP, Rao TN, Langstieh BT, Thangaraj K, Reddy AG, Singh $L$ : Y-chromosome evidence suggests a common paternal heritage of Austro-Asiatic populations. $B M C$ Evol Biol 2007, 7:47.

39. Thurgood G: Phan Rang Cham and Utsat: Tonogenetic themes and variants. In Tonality in Austronesian languages. Oceanic Linguistics Special Publication Volume 24. Edited by: Edmondson JA, Gregerson KJ. Honolulu, University of Hawaii Press; 1993:9I-106.

40. Shikama T, Ling CC, Shimoda N, Baba H: Discovery of fossil Homo sapiens from Chochen in Taiwan. J Anthrop Soc Nippon 1976, 84: $|3|-\mid 38$

4I. Larson G, Cucchi T, Fujita M, Matisoo-Smith E, Robins J, Anderson A, Rolett B, Spriggs M, Dolman G, Kim TH, Thuy NT, Randi E, Doherty M, Due RA, Bollt R, Djubiantono T, Griffin B, Intoh M, Keane E, Kirch P, Li KT, Morwood M, Pedriña LM, Piper PJ, Rabett RJ, Shooter P, Bergh G Van den, West E, Wickler S, Yuan J, Cooper A, Dobney K: Phylogeny and ancient DNA of Sus provides insights into neolithic expansion in Island Southeast Asia and Oceania. Proc Natl Acad Sci USA 2007, 104:4834-4839.

42. Capelli C, Wilson JF, Richards M, Stumpf MP, Gratrix F, Oppenheimer S, Underhill P, Pascali VL, Ko TM, Goldstein DB: A Predominantly Indigenous Paternal Heritage for the Austronesian-Speaking Peoples of Insular Southeast Asia and Oceania. Am J Hum Genet 200I, 68:432-443.

43. Underhill PA, Shen P, Lin AA, Jin L, Passarino G, Yang WH, Kauffman E, Bonne-Tamir B, Bertranpetit J, Francalacci P, Ibrahim M, Jenkins T, Kidd JR, Mehdi SQ, Seielstad MT, Wells RS, Piazza A, Davis RW, Feldman MW, Cavalli-Sforza LL, Oefner PJ: Y chromosome sequence variation and the history of human populations. Nat Genet 2000, 26:358-36I.

44. Hurles ME, Irven C, Nicholson J, Taylor PG, Santos FR, Loughlin J, Jobling MA, Sykes BC: European Y-chromosomal lineages in Polynesians: a contrast to the population structure revealed by mtDNA. Am J Hum Genet 1998, 63: 1793-1806.

45. Lum JK, Cann RL, Martinson JJ, Jorde LB: Mitochondrial and Nuclear Genetic Relationships among Pacific Island and Asian Populations. Am J Hum Genet 1998:613-624.

46. Kayser M, Brauer S, Weiss G, Underhill PA, Roewer L, Schiefenhovel W, Stoneking M: Melanesian origin of Polynesian Y chromosomes. Curr Biol 2000, 10:1237-1246.

47. Terrell JE, Kelly KM, Rainbird P: Foregone conclusions? In search of 'Papuans' and 'Austronesians'. Curr Anthropol 200I, 42:97-I 24

48. Hill C, Soares P, Mormina M, Macaulay V, Meehan W, Blackburn J, Clarke D, Raja JM, Ismail P, Bulbeck D, Oppenheimer S, Richards M: Phylogeography and ethnogenesis of aboriginal Southeast Asians. Mol Biol Evol 2006, 23:2480-249I.

49. Hill C, Soares P, Mormina M, Macaulay V, Clarke D, Blumbach PB, Vizuete-Forster M, Forster P, Bulbeck D, Oppenheimer S, Richards M: A mitochondrial stratigraphy for island southeast Asia. Am J Hum Genet 2007, 80:29-43.

50. The $Y$ chromosome consortium: A nomenclature system of the tree of human Y-chromosomal binary haplogroup. Genome Res 2002, I 2:339-348.

5I. Kayser M, Caglià A, Corach D, Fretwell N, Gehrig C, Graziosi G, Heidorn F, Herrmann S, Herzog B, Hidding M, Honda K, Jobling M, Krawczak M, Leim K, Meuser S, Meyer E, Oesterreich W, Pandya A, Parson W, Penacino G, Perez-Lezaun A, Piccinini A, Prinz M, Schmitt
C, Roewer L: Evaluation of Y-chromosomal STRs: a multicenter study. Int J Legal Med 1997, I I 0:125-133.

52. Dupanloup I, Bertorelle G: Inferring admixture proportions from molecular data: extension to any number or parental populations. Mol Biol Evol 200I, 18:672-675.

53. Slatkin M: A measure of population subdivision based on microsatellite allele frequencies. Genetics 1995, 139:457-462.

54. Schneider S, Roessli D, Excoffier L: Arlequin: Ver. 2.000. A software for population genetic analysis Geneva, Genetics and Biometry Laboratory, Univ. of Geneva; 2000.

55. Nei M: Molecular evolutionary genetics New York, Columbia University Press; 1987.

56. Kimmel M, Chakraborty R: Measures of variation at DNA repeat loci under a general stepwise mutation model. Theor Popul Biol 1996, 50:345-367.

57. Zhivotovsky LA, Underhill PA, Cinnioğlu C, Kayser M, Morar B, Kivisild T, Scozzari R, Cruciani F, Destro-Bisol G, Spedini G, Chambers GK, Herrera RJ, Yong KK, Gresham D, Tournev I, Feldman MW, Kalaydjieva $L$ : The effective mutation rate at $Y$ chromosome short tandem repeats, with application to human population-divergence time. Am J Hum Genet 2004, 74:50-6I.
Publish with Bio Med Central and every scientist can read your work free of charge

"BioMed Central will be the most significant development for disseminating the results of biomedical research in our lifetime. "

Sir Paul Nurse, Cancer Research UK

Your research papers will be:

- available free of charge to the entire biomedical community

- peer reviewed and published immediately upon acceptance

- cited in PubMed and archived on PubMed Central

- yours - you keep the copyright
BiolMedcentral 